\title{
7
}

\section{Crystallization and Thermal Properties of Biofiber-Polypropylene Composites}

\author{
M. Soleimani ${ }^{1}$, L. Tabil ${ }^{1}$, S. Panigrahi ${ }^{1}$ and I. Oguocha ${ }^{2}$ \\ ${ }^{1}$ Department of Chemical and Biological Engineering, University of Saskatchewan \\ 2Department of Mechanical Engineering, University of Saskatchewan \\ Saskatoon, \\ Canada
}

\section{Introduction}

The crystallization of small molecules proceeds by nucleation and growth mechanisms. In polymers, the basic morphology of the crystals is spherulite lamellar crystal bundles which results from the growth of a nucleus center followed by branching to form radial structural equivalence. According to reported observations (Reiter \& Strobl 2007), the long-chain fractions in spherulites enriched in early-formed thick crystals are called dominant lamellae and the short-chain fractions enriched in later-formed thin crystals are called subsidiary lamellae.

Polypropylene (PP) is an attractive thermoplastic polymer with exceptional properties such as high isotacticity, high cost-performance ratio, low processing temperature, excellent chemical and moisture resistance, low density and good ductility (Somnuk et al. 2007 ; Zhang et al. 2002). However, it has some inferior mechanical properties such as low impact resistance and low stiffness, both of which can be improved upon by using additives such as tougheners and the application of nucleating agents (Zhang et al. 2002).

The application of nucleating agents results in the shortening of injection molding cycle and, consequently, in the reduction of manufacturing costs. Also, optical and mechanical properties of polymers can be improved by the generation of small spherulites. As a common industrial practice, polymers are often mixed with other materials to improve properties such as strength and biodegradability or to save the starting materials (Mucha \& Krolikowski 2003).

As a coupling agent used for in situ or reactive compatibilization, maleic anhydride-grafted polypropylene (MAPP) has the same molecular structure as polypropylene while the maleic anhydride group is attached to the backbone. In a study by Seo et al. (2000), it was reported that the mechanism of crystallization in isotactic polypropylene (iPP) could be different from that of MAPP due to their different nucleation mechanisms originating from the differences in their characteristics and the number of heterogeneous nuclei. Also, the diffusional activation energy and crystallization half-time were found to be smaller for MAPP than for iPP under isothermal conditions. The rate of crystallization was decreased 
by increasing temperature under isothermal conditions for both materials, however, it was much more noticeable for iPP. The application of MAPP in iPP affected its crystallization during the cooling process because of the increase in the number of effective nuclei.

In this paper, non-isothermal crystallization melt behaviour and thermal properties of PP composite materials with different formulations were studied with respect to the effects of chemical modification, the use of compatibilizer, and fiber loading. For this purpose, different theories and models were used to analyze the data obtained in this investigation.

\section{Materials and methods}

\subsection{Materials}

A compression-grade PP (PRO-FAX) with density of $0.904 \mathrm{~g} \mathrm{~cm}^{-3}$, melt flow index of $0.65 \mathrm{~g} / 10$ min at $230^{\circ} \mathrm{C}$, and low melt flow index $\left(\mathrm{MFI}=0.65 \mathrm{~g} / 10 \mathrm{~min}\right.$ at $230^{\circ} \mathrm{C}$ ) was obtained from Ashland Specialty Chemical Company (Vancouver, BC, Canada), while maleic anhydridegrafted polypropylene $(\mathrm{MAPP})\left(\mathrm{MFI}=115 \mathrm{~g} / 10 \mathrm{~min}\right.$ at $190^{\circ} \mathrm{C}$; maleic acid content of approximately $0.6 \%$ ) was obtained from Aldrich Chemical Company (Toronto, ON, Canada). Flax fiber which was already retted with a density of $1.52 \mathrm{~g} \mathrm{~cm}^{-3}$ was obtained from Biofiber Ltd., Canora, SK, Canada. For mercerization, the fiber was first washed with a $2 \%$ commercially available detergent solution (Ultra liquid Tide containing cationic and non-ionic biodegradable detergents) and then washed with distilled water to eliminate extractives, especially waxy materials. After drying at $60^{\circ} \mathrm{C}$ for $24 \mathrm{~h}$, it was pretreated with a $5 \%$ sodium hydroxide $(\mathrm{NaOH})$ solution for $3 \mathrm{~h}$ and thoroughly washed with distilled water and dried again in an oven (Despatch Oven Co., Minneapolis, MN, USA). Fiber analysis for measurement of the components was performed based on the measurement of neutral detergent fiber (NDF), acid detergent fiber (ADF) and acid detergent lignin (ADL) using a fiber analyzer (ANKOM Technology, Fairport, NY, USA) to determine cellulose, hemicellulose, lignin and ash percentages.

\subsection{Fabrication of composites}

Pretreated and untreated flax fibers were each milled in a grinder (Retsch $\mathrm{GmbH} 5657$ HAAN, West Germany) through a 2-mm opening to be used in composite formulations as shown in Table 1. PP and MAPP were dried in the oven at $60^{\circ} \mathrm{C}$ for $15 \mathrm{~h}$ and at $120^{\circ} \mathrm{C}$ for 15 $\mathrm{h}$, respectively, before use. Materials based on the formulation and after initial mixing were extruded in a single-screw extruder (Akron Inc., Batavia, OH, USA) at temperatures up to $190^{\circ} \mathrm{C}$ with a screw speed of $45 \mathrm{rpm}$ and the extrudates were pelletized to be used for compression molding in a hot press (J.B. Miller Machinery \& Supply Co., Toronto, ON, Canada) under a pressure of $3.5 \mathrm{MPa}$ at $190^{\circ} \mathrm{C}$ for $7 \mathrm{~min}$ to prepare plates with a thickness of about $3.2 \mathrm{~mm}$. Differential scanning calorimetry (DSC) measurements were carried out from small pieces cut from moulded composites.

\subsection{Thermal conductivity and density measurements}

A thermal conductivity analyzer (FOX 200, Saugus, MA, USA) was used to determine the steady-state effective thermal conductivity of the molded polymer and composites at $25^{\circ} \mathrm{C}$ 
in accordance with ASTM C518. 2002. Each run took $0.5 \mathrm{~h}$, but the first 5 min was used to bring the samples to the steady-state condition. The density of the test materials was measured by using a gas (nitrogen)-operated pycnometer (Quantachrome Corp., Boynton Beach, FL, USA) to measure the volume of the samples and their mass was determined using a Galaxy 160D weighing scale (OHAUS Scale Corporation, Florham Park, NJ, USA).

\subsection{Differential scanning calorimetry}

DSC (TA Instruments, New Castle, DE, USA) measurements were performed in a TA Instrument model 2000 DSC equipped with a cooling system to assess crystallization properties of the materials. Samples were heated from $40^{\circ} \mathrm{C}$ to $200^{\circ} \mathrm{C}$ at a heating rate of $10^{\circ} \mathrm{C} / \mathrm{min}$ and held for $5 \mathrm{~min}$ to erase the thermal history of the polymer. Then, the samples were cooled down at the desired rate $\left(5,10,15\right.$ and $\left.20^{\circ} \mathrm{C} / \mathrm{min}\right)$ to analyze and investigate the crystallization kinetics. The degree of crystallinity $\left(X_{c}\right)$ in biocomposites corrected for biofibers was determined by integration of the generated DSC exotherms. The crystallinity of PP or the matrix in the composites was calculated using equation (1).

$$
X_{c} \%=\frac{\Delta H_{c}}{\Delta H_{c}^{0}} \times 100
$$

Where $\Delta \mathrm{H}^{\circ}{ }_{\mathrm{c}}$ is the heat of crystallinity of $100 \%$ crystalline PP assumed to be $146.5 \mathrm{~J} / \mathrm{g}$ (Lonkar, et al. 2009) and $\Delta \mathrm{H}_{\mathrm{c}}$ is taken as the enthalpy of crystallization corrected for biofiber in the composites assuming that the contribution of this fraction is ignored.

\begin{tabular}{ccc}
\hline Fiber & PP/MAPP/Fiber & Formulation $(\%)$ \\
\hline- & PP & $100 / 0 / 0$ \\
\hline \multirow{3}{*}{ Untreated fiber } & C1 & $85 / 0 / 15$ \\
& C2 & $80 / 5 / 15$ \\
& C3 & $70 / 0 / 30$ \\
Alkaline treated fiber & C4 & $65 / 5 / 30$ \\
\hline & C5 & $85 / 0 / 15$ \\
& C6 & $80 / 5 / 15$ \\
& C7 & $70 / 0 / 30$ \\
\hline
\end{tabular}

Table 1. Components of the composites based on polypropylene and flax fiber.

\section{Results and discussion}

Chemical analysis of the (retted) flax fiber before pretreatment showed that the mass fractions of cellulose, hemicellulose and lignin were $80.9 \%, 7.9 \%$ and $1.4 \%$, respectively. These changed to $85 \%, 6.2 \%$ and $1.2 \%$, respectively, after mercerization.

\subsection{Thermal conductivity}

The thermal conductivity values determined at $25^{\circ} \mathrm{C}$ for the slab-shaped test materials are given in Table 2. It can be seen that thermal conductivity decreased in all composites 
compared to the unreinforced plain PP which means that flax fiber can increase the thermal insulation property of polymers. The reduction in thermal conductivity is due to the inherent low thermal conductivity of cellulosic materials in comparison to the unreinforced plain polymer. A close observation shows that the thermal conductivity of the composites C6 and C8 (those containing treated fiber, plain PP and MAPP) was slightly higher than similar composites reinforced with untreated fiber (i.e., $\mathrm{C} 2$ and $\mathrm{C} 4$ ). This is probably due to the ability of MAPP to improve cross links between the fiber and matrix as reported by Kim et al. (2006).

\begin{tabular}{cccc}
\hline Fiber & Material & $\begin{array}{c}\text { Density } \\
\left(\mathrm{g} \mathrm{cm}^{-3}\right)\end{array}$ & $\begin{array}{c}\text { Thermal conductivity } \\
\left(\mathrm{W} / \mathrm{m}^{\circ} \mathrm{C}\right)\end{array}$ \\
\hline \multirow{3}{*}{ Untreated fiber } & PP & 0.901 & 0.152 \\
\hline & $\mathrm{C} 1$ & 0.956 & 0.133 \\
& $\mathrm{C} 2$ & 0.957 & 0.133 \\
& $\mathrm{C} 3$ & 1.006 & 0.126 \\
Alkaline treated fiber & $\mathrm{C} 4$ & 1.013 & 0.126 \\
& $\mathrm{C} 5$ & 0.964 & 0.135 \\
& $\mathrm{C} 6$ & 0.963 & 0.137 \\
& $\mathrm{C} 7$ & 1.021 & 0.130 \\
& $\mathrm{C} 8$ & 1.022 & 0.133 \\
\hline
\end{tabular}

Table 2. Density and thermal conductivity of PP (polypropylene) and composites(C1 to C8 as indicated by Table 1).

\subsection{Crystallization behavior}

Figure 1 shows the DSC exotherms obtained for samples cooled from the melt at different cooling rates $\left(5\right.$ to $\left.20^{\circ} \mathrm{C} / \mathrm{min}\right)$. The crystallization temperature $\left(\mathrm{T}_{\mathrm{c}}\right)$ and crystallinity $\left(\mathrm{X}_{\mathrm{c}} \%\right)$ of the test materials are presented in Table 3.

The effect of cooling rate on the shape and relative position of the peak temperature (i.e., crystallization temperature, $\mathrm{T}_{\mathrm{c}}$ ) of the exotherms can be readily discerned from Figure 1 and Table 3. All the curves shifted to lower temperatures as heating rate increased. It can be observed that the higher the cooling rate, the lower the crystallization temperature and degree of crystallinity. The data indicate that the average shift in crystallization temperature for composites is approximately $6^{\circ} \mathrm{C}$ as the cooling rate increased from 5 to $20^{\circ} \mathrm{C} / \mathrm{min}$. For pure PP, it is about $4^{\circ} \mathrm{C}$. The crystallinity of both pure PP and composites decreased with the cooling rate apparently because the low cooling rates provide higher fluidity and diffusivity for the polymer matrix molecules, thereby improving secondary crystallization and inducing more crystallinity at high temperatures than at high cooling rates. Furthermore, the results also indicate that the addition of fiber increased crystallinity of the test materials. This is attributed to the nucleation effect of the fibers which provide nucleation sites and facilitate crystallization of the polymer as well as transcrystallinity (Somnuk et al. 2007). It can also be discerned from Table 3 that the contribution of biofiber in the composites not only increased crystallinity of the material, but also increased crystallization temperature at the same cooling rate (Table 3). 

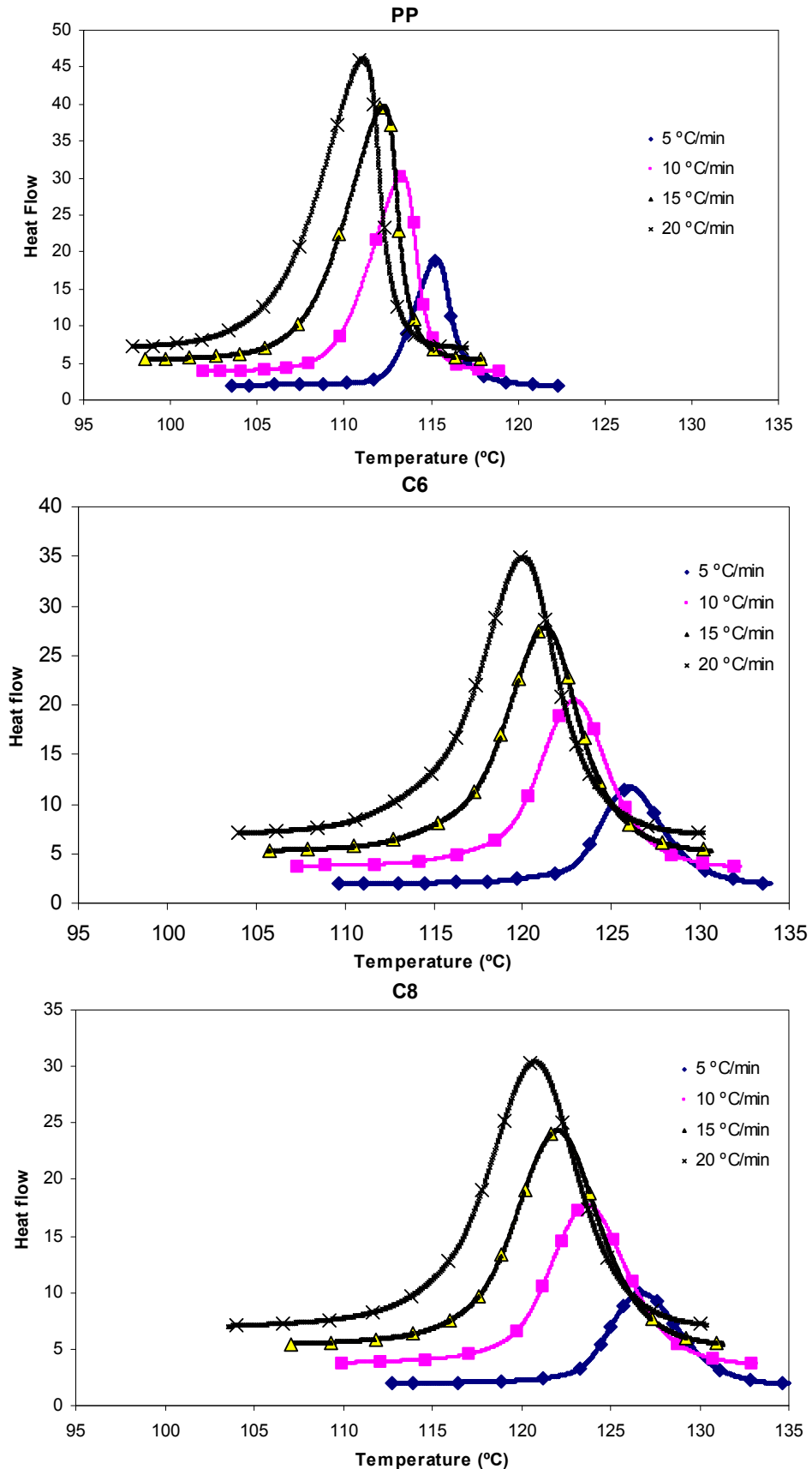

Fig. 1. Non-isothermal crystallization thermograms of PP (polypropylene), C6 (PP/MAPP/Fiber: 80/5/15) and C8 (PP/MAPP/Fiber: 65/5/30) at different cooling rates. 


\begin{tabular}{|c|c|c|c|c|c|c|c|c|}
\hline Formulation & \multicolumn{2}{|c|}{$5{ }^{\circ} \mathrm{C} / \mathrm{min}$} & \multicolumn{2}{c|}{$10{ }^{\circ} \mathrm{C} / \mathrm{min}$} & \multicolumn{2}{c|}{$15{ }^{\circ} \mathrm{C} / \mathrm{min}$} & \multicolumn{2}{c|}{$20{ }^{\circ} \mathrm{C} / \mathrm{min}$} \\
\cline { 2 - 8 } & $\begin{array}{c}\mathrm{T}_{\mathrm{c}} \\
\left({ }^{\circ} \mathrm{C}\right)\end{array}$ & $\mathrm{X}_{\mathrm{c}}(\%)$ & $\begin{array}{c}\mathrm{T}_{\mathrm{c}} \\
\left({ }^{\circ} \mathrm{C}\right)\end{array}$ & $\mathrm{X}_{\mathrm{c}}(\%)$ & $\begin{array}{c}\mathrm{T}_{\mathrm{c}} \\
\left({ }^{\circ} \mathrm{C}\right)\end{array}$ & $\mathrm{X}_{\mathrm{c}}(\%)$ & $\begin{array}{c}\mathrm{T}_{\mathrm{c}} \\
\left({ }^{\circ} \mathrm{C}\right)\end{array}$ & $\mathrm{X}_{\mathrm{c}}(\%)$ \\
\hline $\mathrm{PP}$ & 115.3 & 59.5 & 113.4 & 59.1 & 112.2 & 59.6 & 111.1 & 58.2 \\
$\mathrm{C} 1$ & 123.4 & 63.1 & 120.1 & 62.9 & 118.3 & 62.1 & 116.9 & 61.2 \\
$\mathrm{C} 2$ & 125.1 & 62.3 & 122.3 & 62.5 & 120.5 & 61.0 & 119.3 & 61.0 \\
$\mathrm{C} 3$ & 124.8 & 66.4 & 121.7 & 65.9 & 120.0 & 65.2 & 118.7 & 65.1 \\
$\mathrm{C} 4$ & 126.1 & 63.2 & 123.1 & 62.0 & 121.4 & 61.0 & 120.1 & 60.0 \\
$\mathrm{C} 5$ & 122.6 & 62.1 & 119.2 & 61.9 & 117.3 & 60.5 & 115.9 & 60.2 \\
$\mathrm{C} 6$ & 125.3 & 61.4 & 122.0 & 60.3 & 120.4 & 60.1 & 119.1 & 60.0 \\
$\mathrm{C} 7$ & 124.5 & 65.2 & 121.0 & 64.2 & 119.3 & 64.0 & 118.1 & 63.1 \\
$\mathrm{C} 8$ & 126.3 & 62.8 & 123.3 & 61.8 & 121.5 & 60.9 & 120.3 & 60.5 \\
\hline
\end{tabular}

PP: polypropylene; $\mathrm{C}_{1}$ to $\mathrm{C}_{8}$ : composites; $\mathrm{T}_{\mathrm{c}}$ : crystallization temperature; $\mathrm{X}_{\mathrm{c}}$ : crystallinity.

Table 3. Crystallization temperature and crystallinity of PP and biocomposites at different cooling rates $\left(5,10,15\right.$ and $\left.20^{\circ} \mathrm{C} / \mathrm{min}\right)$.

The use of the compatibilizer seems to have reduced the level of crystallinity in the composites for the same levels of fiber loading, while it resulted in a marginal increase in the crystallization temperature. For instance, at the cooling rate of $5^{\circ} \mathrm{C} / \mathrm{min}$, the crystallization temperature increased from $124.5^{\circ} \mathrm{C}$ to $126.3^{\circ} \mathrm{C}$, while the crystallinity decreased from $65.2 \%$ to $62.8 \%$ for $\mathrm{C} 7$ and $\mathrm{C} 8$, respectively; and this could be attributed to the application of MAPP in C8. In the same vein, chemical pretreatment seems to marginally reduce the degree of crystallinity for all composites irrespective of their fiber content in comparison with composites reinforced with the untreated fiber with or without the compatibilizer. Therefore, among all formulations, the highest value of crystallinity was obtained for composite sample $\mathrm{C} 3$ at the cooling rate of $5^{\circ} \mathrm{C} / \mathrm{min}$.

Fiber mercerization also slightly caused the reduction of crystallization temperature at the constant level of fiber loading as well as constant cooling rate only for samples without MAPP, but it almost did not have any influence on crystallization temperature with the presence of MAPP. For example, at the cooling rate of $10^{\circ} \mathrm{C} / \mathrm{min}$, crystallization temperature changed from $120.1^{\circ} \mathrm{C}$ for $\mathrm{C} 1$ to $119.2^{\circ} \mathrm{C}$ for $\mathrm{C} 5$ and this is only because of the chemical modification.

The values of onset temperature $\left(T_{0}\right)$, end temperature of crystallization exotherm $\left(T_{e}\right)$, peak time $\left(t_{c}\right)$ and half crystallization time $\left(t_{0.5}\right)$ determined for all samples at different cooling rates are summarized in Table 4 . It can be seen that these four parameters decreased with increasing cooling rate. The application of MAPP in the composites reduced the half-time of crystallization for composites reinforced with pretreated and untreated biofiber. For example, $t_{0.5}$ decreased from 55 to $48 \mathrm{~s}$ for $\mathrm{C} 7$ and $\mathrm{C} 8$ at $5^{\circ} \mathrm{C} / \mathrm{min}$, respectively. However, the magnitude of reduction in half-time due to the compatibilizer was less at high cooling rates. Also, a comparison of the data in Table 4 indicates that chemical pretreatment of the fiber increased the magnitude of $t_{0.5}$ in the biocomposites at the same level of fiber content and cooling rate. This result is consistent with those reported by Garbarczyk et al. (2000) who observed that PP crystallized faster when reinforced with untreated natural fiber than with chemically modified fibers. Furthermore, a close look at the data shows that lowest value of half crystallization time occurred in pure PP for all cooling rates. Although its crystallinity is lower at all cooling rates, it is observed that non-isothermal crystallization occurred faster in PP than in the biocomposites. 


\begin{tabular}{|c|c|c|c|c|c|c|c|c|c|c|c|c|c|c|c|c|}
\hline \multirow{2}{*}{$\begin{array}{c}\text { Formu- } \\
\text { lation }\end{array}$} & \multicolumn{4}{|c|}{$5^{\circ} \mathrm{C} / \mathrm{min}$} & \multicolumn{4}{|c|}{$10^{\circ} \mathrm{C} / \mathrm{min}$} & \multicolumn{4}{|c|}{$15^{\circ} \mathrm{C} / \mathrm{min}$} & \multicolumn{4}{|c|}{$20^{\circ} \mathrm{C} / \mathrm{min}$} \\
\hline & $\begin{array}{c}\mathrm{T}_{0} \\
\left({ }^{\circ} \mathrm{C}\right)\end{array}$ & $\begin{array}{c}\mathrm{T}_{\mathrm{e}} \\
\left({ }^{\circ} \mathrm{C}\right)\end{array}$ & $\begin{array}{l}t_{c} \\
\text { (s) }\end{array}$ & $\begin{array}{l}\mathrm{t}_{0.5} \\
\text { (s) }\end{array}$ & $\begin{array}{c}\mathrm{T}_{0} \\
\left({ }^{\circ} \mathrm{C}\right)\end{array}$ & $\begin{array}{c}\mathrm{T}_{\mathrm{e}} \\
\left({ }^{\circ} \mathrm{C}\right)\end{array}$ & $\begin{array}{l}t_{c} \\
\text { (s) }\end{array}$ & $\begin{array}{l}\mathrm{t}_{0.5} \\
\text { (s) }\end{array}$ & $\begin{array}{c}\mathrm{T}_{0} \\
\left({ }^{\circ} \mathrm{C}\right)\end{array}$ & $\begin{array}{c}\mathrm{T}_{\mathrm{e}} \\
\left({ }^{\circ} \mathrm{C}\right)\end{array}$ & $\begin{array}{l}t_{c} \\
\text { (s) }\end{array}$ & $\begin{array}{l}\mathrm{t}_{0.5} \\
\text { (s) }\end{array}$ & $\begin{array}{c}\mathrm{T}_{0} \\
\left({ }^{\circ} \mathrm{C}\right)\end{array}$ & $\begin{array}{c}\mathrm{T}_{\mathrm{e}} \\
\left({ }^{\circ} \mathrm{C}\right)\end{array}$ & $\begin{array}{l}t_{c} \\
\text { (s) }\end{array}$ & $\begin{array}{l}\mathrm{t}_{0.5} \\
\text { (s) }\end{array}$ \\
\hline $\mathrm{PP}$ & 116.9 & 103.3 & 29 & 26 & 114.9 & 101.9 & 17 & 16 & 113.7 & 98.5 & 13 & 13 & 112.7 & 97.8 & 10 & 10 \\
\hline C 1 & 3.0 & 111.4 & 59 & 55 & 2 & 4.2 & 34 & 31 & 5 & 103.3 & 25 & 23 & 122.3 & 102.1 & F & 12 \\
\hline C & 8 & 12.5 & 5 & 46 & 125.9 & .1 & 2 & 25 & 124.2 & 106.1 & 19 & 18 & 122.9 & 104.7 & 14 & \\
\hline $\mathrm{C}_{3}^{3}$ & 3.6 & 2 & 5 & 49 & 12 & .8 & 2 & 28 & 124.3 & 105.9 & 21 & 20 & 123.2 & 103.1 & 17 & \\
\hline C4 & 0.1 & 109.7 & 53 & 48 & 127.3 & 10.2 & 2 & 26 & 125.7 & 107.8 & 20 & 19 & 124.4 & 104.5 & 16 & 15 \\
\hline 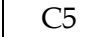 & 7.4 & 110.2 & 61 & 57 & 124.4 & 04.9 & 34 & 32 & 122.7 & 104.7 & 25 & 23 & 121.5 & 102.1 & 20 & 19 \\
\hline C6 & 29.2 & 111.8 & 52 & 48 & 126.1 & 08.3 & 29 & 27 & 124.4 & 106.4 & 20 & 19 & 123.1 & 103.8 & 16 & 15 \\
\hline C7 & 128.9 & 111.1 & 57 & 55 & 125.9 & 109.5 & 32 & 31 & 124.3 & 105.9 & 23 & 22 & 123.2 & 103.5 & 18 & 17 \\
\hline C8 & 130.4 & 112.8 & 53 & 48 & 127.6 & 123.3 & 30 & 28 & 126.0 & 109.0 & 21 & 19 & 124.8 & 105.2 & 17 & 16 \\
\hline
\end{tabular}

PP: polypropylene; $\mathrm{C}_{1}$ to $\mathrm{C}_{8}$ : composites; $\mathrm{T}_{0}$ : onset temperature, $\mathrm{T}_{\mathrm{e}}$ : end temperature of crystallization, $\mathrm{t}_{\mathrm{c}}$ : peak time and to.5: half crystallization time.

Table 4. Crystallization parameters obtained from DSC exotherms.

\subsection{Modeling of crystallization}

The relative degree of crystallinity $\left(X_{t}\right)$ was calculated from the relationship in equation (2) as:

$$
X_{t}=\frac{\int_{T_{0}}^{T}\left(d H_{c} / d T\right) d T}{\left.\int_{T_{0}}^{T_{\infty}} d H_{c} / d T\right) d T}
$$

where $d H$ denotes the enthalpy of crystallization measured during the time interval $d t$ and $T_{\infty}$ is the end temperature of crystallization. Figure 2 shows typical plots of relative crystallinty vs. temperature obtained for representative samples of the tested materials (PP, C6 and C8). Similar plots were obtained for all samples tested in this study. It can be seen that the shape of the curves is sigmoidal. It can be observed from these plots that, for the cooling rates studied, PP crystallized at lower temperatures than the composite materials.

The activation energy for crystallization $(\Delta \mathrm{E})$ was determined for pure PP and the biocomposite samples using the Kissinger model (1957) shown in equation (3).

$$
\frac{-\Delta E}{R}=\frac{d\left(\ln \left(\varphi / T_{c}^{2}\right)\right)}{d\left(1 / T_{c}\right)}
$$

where $R$ is the universal gas constant (kJ/mol.K) and $\varphi$ is the cooling rate. The values of activation energy for PP and its composites were determined from the slope of the linear plots shown in Figures 3 and 4. It can be seen from Table 4 that the addition of biofiber markedly reduced the activation energy for crystallization in pure PP. The low activation energy for crystallization obtained for the composites is consistent with their high crystallinity reported in Table 3, which could be attributed to the fact that biofibers, being high energy sites, lowered the activation energy for nucleation as similarly reported by Page \& Gopakumar (2006). A close inspection of the data in Table 4 for the composites shows that at each level of fiber content, the application of MAPP increased their activation energy. For instance, it was increased from 287 to $306 \mathrm{~kJ} / \mathrm{mol}$ for C7 and C8, respectively. 
The Avrami model given in equation (4) is used extensively to evaluate the isothermal kinetics of polymer crystallization:

$$
1-X_{t}=\exp \left(-k t^{n}\right)
$$

where $\mathrm{X}_{\mathrm{t}}$ is the relative crystallinity at time $t$ and constant temperature; $k$ is the crystallization rate constant containing the nucleation and growth rates and is temperature dependent; and $n$ is the Avrami index or exponent which depends on the type of nucleation and growth process. Ozawa (1971) extended the Avrami model to non-isothermal processes by assuming that they are the result of infinitely small changes in the isothermal crystallization steps and obtained:

$$
1-X_{t}=\exp \left(-x / \varphi^{m}\right)
$$

where $m$ is the Ozawa exponent which is dependent on the nucleation density and the spherulitic radial growth rate and $x$ is a function of the overall crystallization rate.

The linearized form of equation (5) is given as:

$$
\ln \left[-\ln \left(1-X_{t}\right)\right]=\ln \mathrm{x}-\mathrm{m} \ln \varphi
$$

Hence, a plot of $\ln \left[-\ln \left(1-X_{t}\right)\right]$ vs. $\ln (t)$ has a slope of $m$ and a y-intercept of $\ln (x)$.

By combining the Avrami and Ozawa models, Liu et al. (1997) introduced another crystallization kinetic model:

$$
\ln \varphi=\ln F(T)-a \ln t
$$

where $\mathrm{F}(\mathrm{T})=[\mathrm{x} / \mathrm{k}]^{1 / \mathrm{m}}$ refers to the crystallization kinetic parameter and $a$ is the ratio of the exponents in Avrami and Ozawa models : $a=n / m$

Typical results of kinetic analysis of the DSC data using the Ozawa model are shown in Figure 5 for PP, C6 and C8, while Table 5 summarizes the results for all formulations.

As shown, the maximum value of $x$ for pure PP is much higher than the values obtained for composites indicating that PP crystallized faster than the matrix in the composites. Amongst the composites, it can be observed in Table 5 that the value of $x$ was affected by fiber content or by compatibilizer for a given fiber content. The parameter $m$ decreased with decreasing temperature for all test materials. Its value ranged from 0.6 to 5.0 for PP and from 1 to 4.2 for the composites. The more limited range of $m$ values obtained for the composites indicates that the crystal growth rate of spherulites was higher in PP than in the composites. This agrees with the result reported by Somnuk et al. (2007) for PP and natural fiber-based composites such that the spherulitic growth rate was higher in neat PP than composites. However, in their study, composites exhibited a higher rate of crystallization compared to neat PP which is different from the result in this study. The $F(T)$ values obtained from the Liu et al. (1997) model increased systematically with the relative crystallinity of pure PP and composites as shown in Table 6. Also, at a given relative crystallinity, the values of $\mathrm{F}(\mathrm{T})$ are lower for PP than for the composites at most levels of $X_{t}$ which indicates that crystallization was faster in pure pp compared to the composites. Furthermore, the application of MAPP in the composites resulted in low values of $\mathrm{F}(\mathrm{T})$ or higher crystallization rates. 

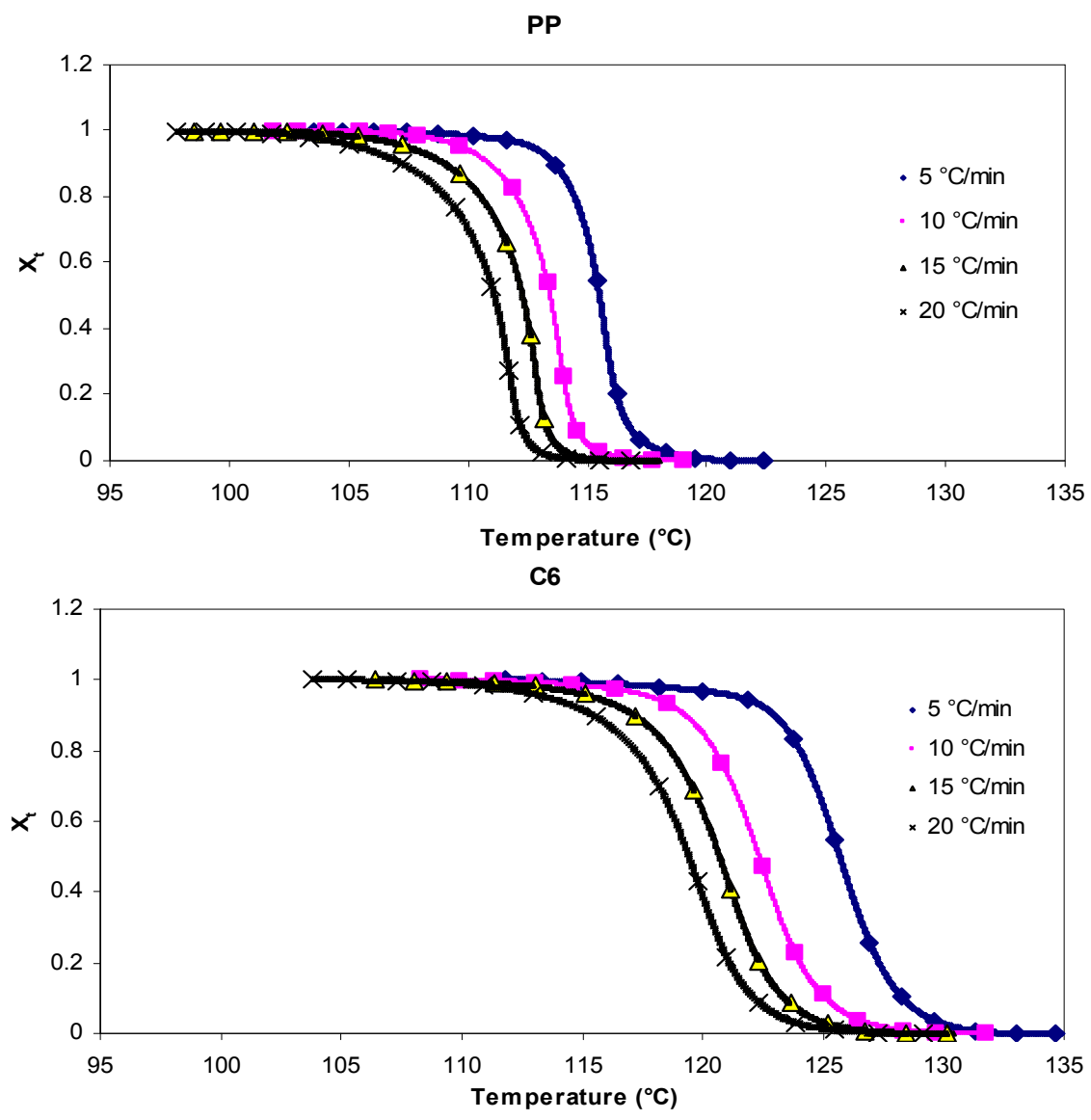

C8

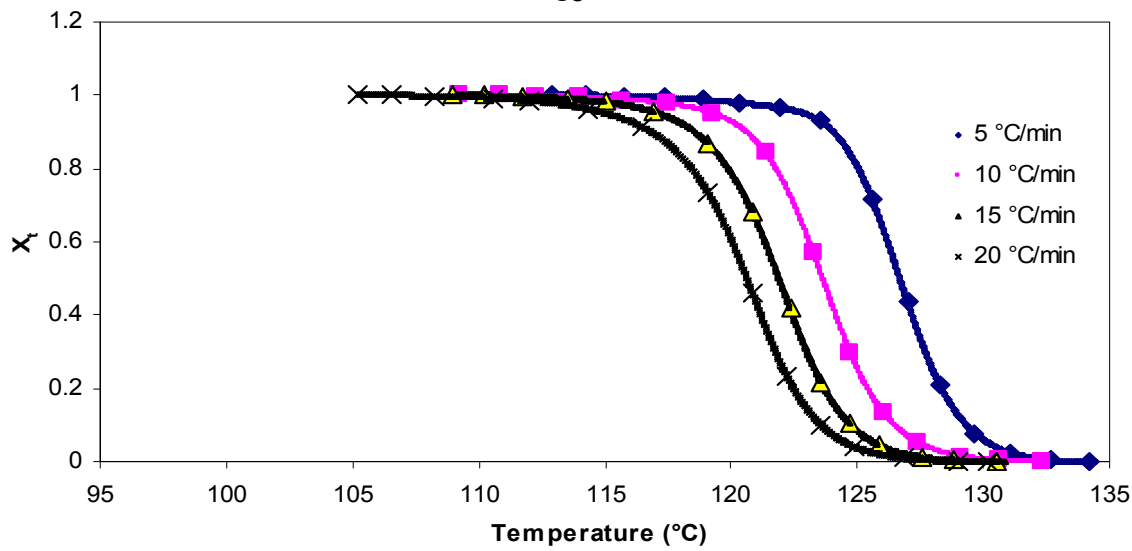

Fig. 2. Relative crystallinity of PP (polypropylene), C6 (PP/MAPP/Fiber: 80/5/15) and C8 (PP/MAPP/Fiber: 65/5/30) at different cooling rates. 


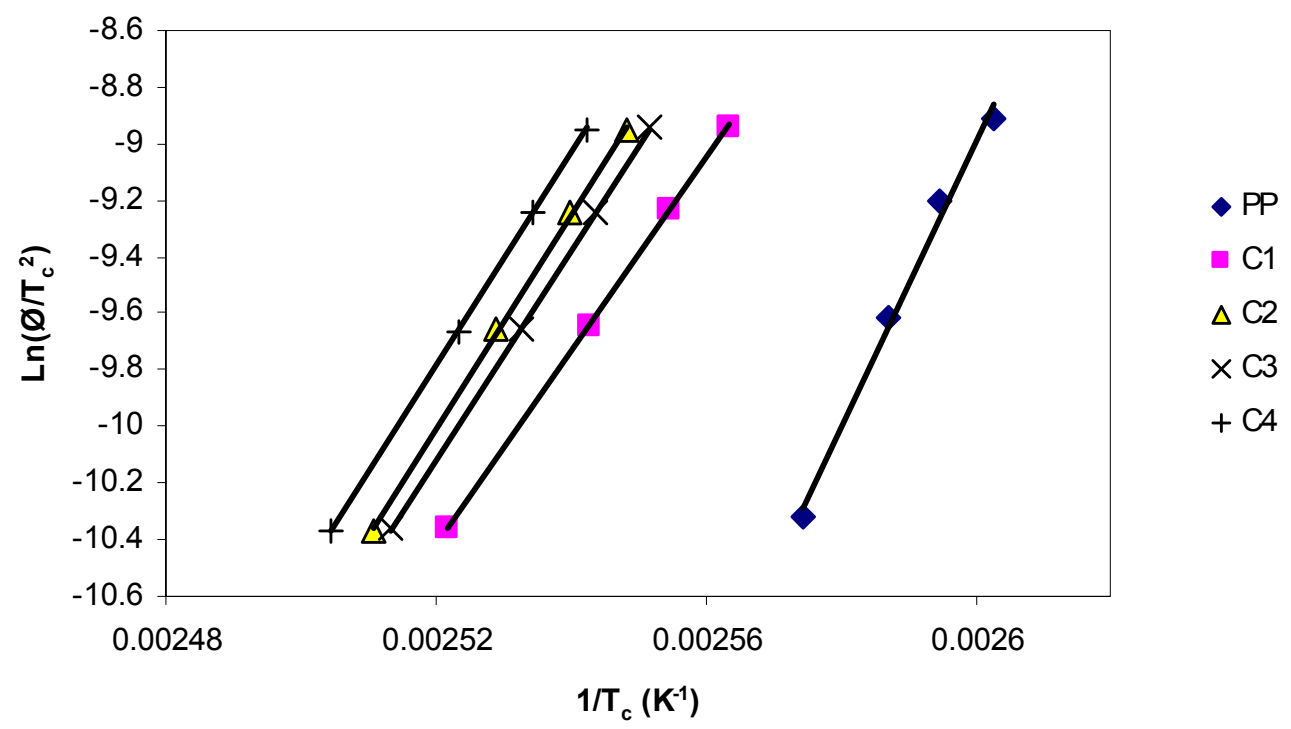

Fig. 3. Kissinger plots of crystallization activation energies of $\mathrm{PP}(419 \mathrm{~kJ} / \mathrm{mol})$ and noncompatibilized formulations: C1 (292 kJ/mol ), C2 (314 kJ/mol), C3 $(297 \mathrm{~kJ} / \mathrm{mol})$ and C4 (310 kJ/mol). PP: polypropylene ; C1, C2, C3 and C4: composites formulations.

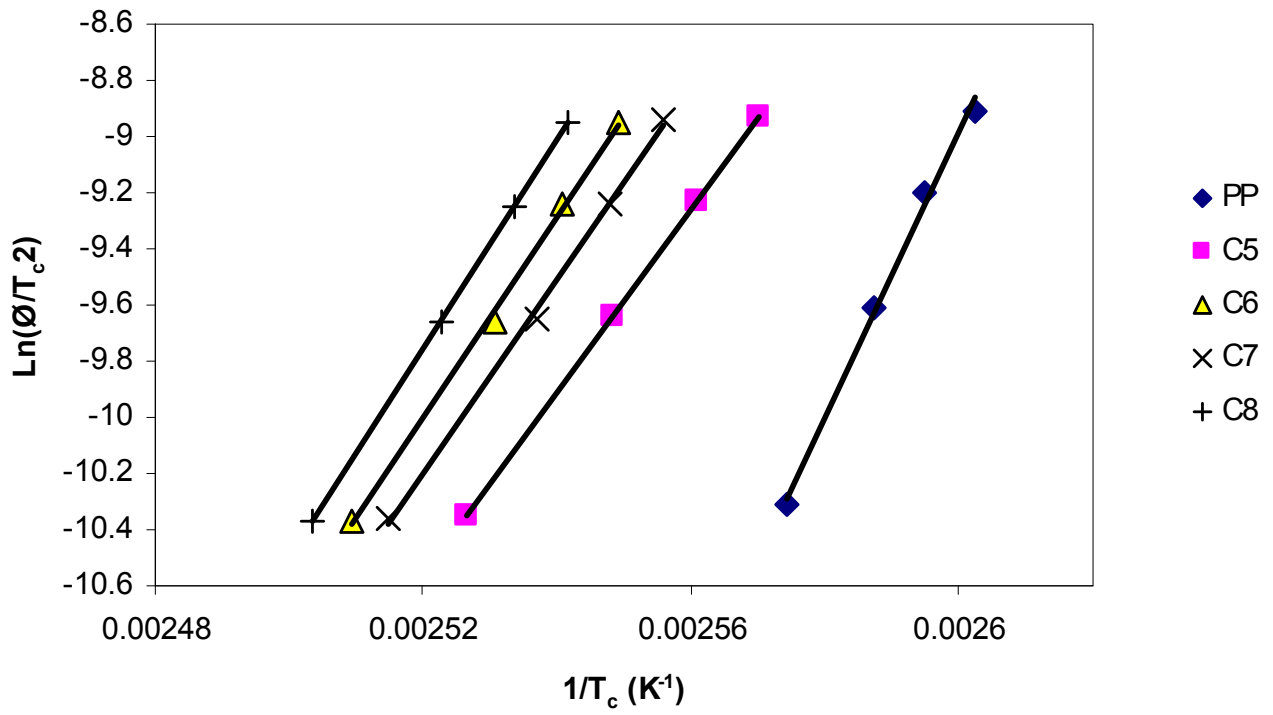

Fig. 4. Kissinger plots of crystallization activation energies of $\mathrm{PP}(419 \mathrm{~kJ} / \mathrm{mol})$ and compatibilized formulations: C5 (272 kJ/mol), C6 (297 kJ/mol), C7 (287 kJ/mol) and C8 (306 kJ/mol). PP: polypropylene ; C5, C6, C7 and C8: composites formulations. 

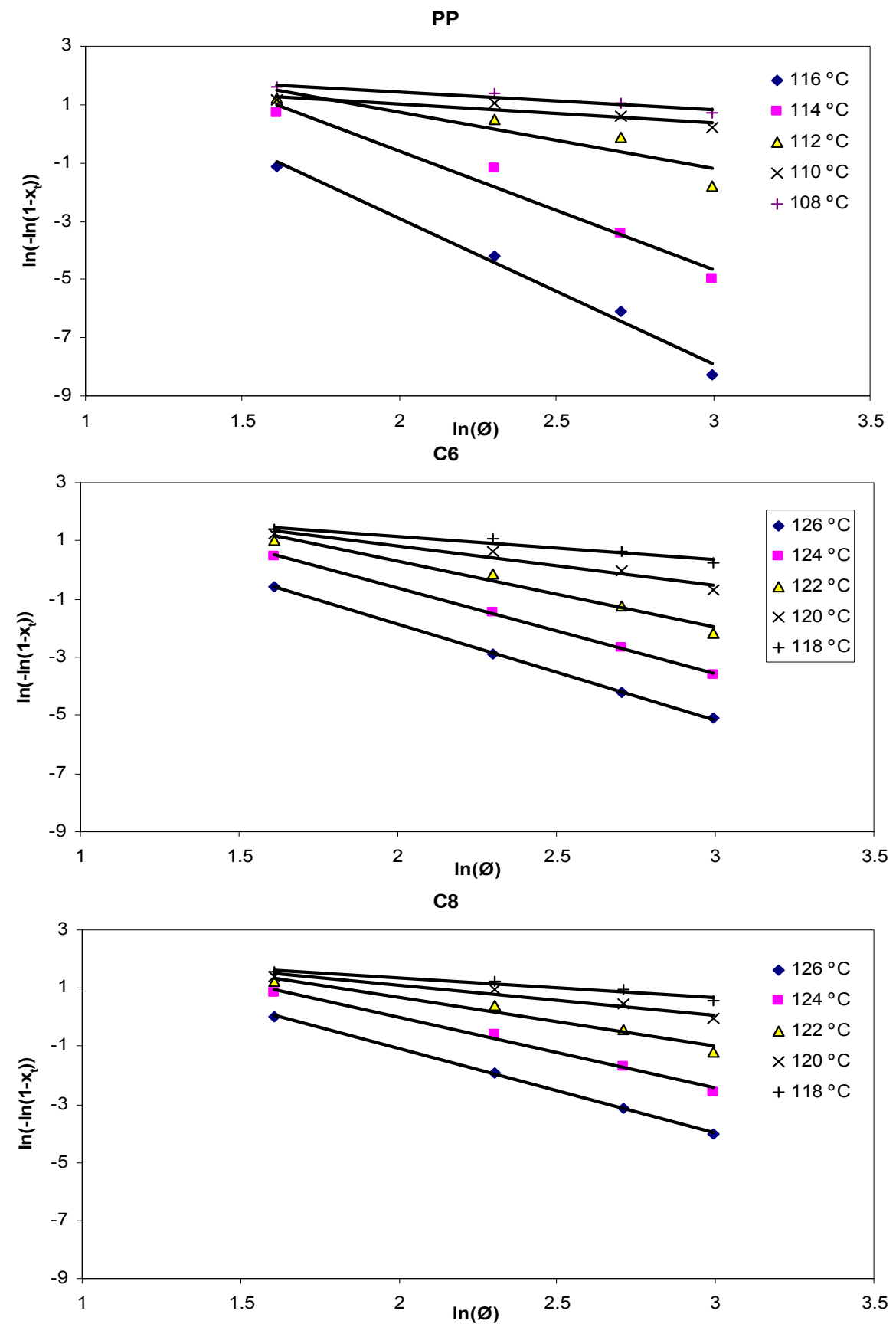

Fig. 5. Ozawa plots for non-isothermal melt crystallization of polypropylene (PP) and composites : C6 (PP/MAPP/Fiber: 80/5/15) and C8 (PP/MAPP/Fiber: 65/5/30). 


\begin{tabular}{|c|c|c|c|c|}
\hline Material & $\mathrm{T}\left({ }^{\circ} \mathrm{C}\right)$ & $\mathrm{m}$ & $x$ & $\mathrm{R}^{2}$ \\
\hline \multirow{5}{*}{$\mathrm{PP}$} & 108 & 0.6 & 14.9 & 0.92 \\
\hline & 110 & 0.7 & 10.0 & 0.83 \\
\hline & 112 & 1.9 & 99.5 & 0.84 \\
\hline & 114 & 4.1 & 1998.2 & 0.96 \\
\hline & 116 & 5.0 & 1212.0 & 0.99 \\
\hline \multirow[t]{5}{*}{$\mathrm{C} 1$} & 118 & 1.4 & 40.4 & 0.97 \\
\hline & 120 & 2.0 & 81.5 & 0.99 \\
\hline & 122 & 2.5 & 99.5 & 0.99 \\
\hline & 124 & 2.9 & 73.4 & 1.00 \\
\hline & 126 & 3.4 & 49.4 & 1.00 \\
\hline \multirow[t]{5}{*}{$\mathrm{C} 2$} & 118 & 0.8 & 16.4 & 0.96 \\
\hline & 120 & 1.3 & 33.1 & 0.94 \\
\hline & 122 & 2.2 & 109.9 & 0.96 \\
\hline & 124 & 2.9 & 164.0 & 1.00 \\
\hline & 126 & 3.3 & 99.5 & 1.00 \\
\hline \multirow[t]{5}{*}{$\mathrm{C} 3$} & 118 & 1.0 & 22.2 & 0.98 \\
\hline & 120 & 1.5 & 40.4 & 0.97 \\
\hline & 122 & 2.3 & 99.5 & 0.98 \\
\hline & 124 & 3.0 & 148.4 & 1.00 \\
\hline & 126 & 3.6 & 121.5 & 0.99 \\
\hline \multirow[t]{5}{*}{$\mathrm{C} 4$} & 118 & 0.7 & 14.9 & 0.92 \\
\hline & 120 & 1.0 & 22.2 & 0.93 \\
\hline & 122 & 1.8 & 66.7 & 0.96 \\
\hline & 124 & 2.5 & 148.4 & 0.99 \\
\hline & 126 & 3.1 & 134.3 & 1.00 \\
\hline \multirow[t]{5}{*}{ C5 } & 118 & 1.8 & 66.7 & 0.99 \\
\hline & 120 & 2.3 & 109.9 & 0.99 \\
\hline & 122 & 2.8 & 109.9 & 1.00 \\
\hline & 124 & 3.3 & 81.5 & 1.00 \\
\hline & 126 & 4.2 & 109.9 & 0.99 \\
\hline \multirow[t]{5}{*}{ C6 } & 118 & 0.8 & 16.4 & 0.94 \\
\hline & 120 & 1.3 & 36.6 & 0.95 \\
\hline & 122 & 2.3 & 121.5 & 0.98 \\
\hline & 124 & 2.9 & 200.3 & 1.00 \\
\hline & 126 & 3.3 & 109.9 & 1.00 \\
\hline \multirow[t]{5}{*}{$\mathrm{C} 7$} & 118 & 1.1 & 27.1 & 0.97 \\
\hline & 120 & 1.7 & 44.7 & 0.98 \\
\hline & 122 & 2.3 & 90.0 & 0.99 \\
\hline & 124 & 2.7 & 81.5 & 1.00 \\
\hline & 126 & 3.0 & 36.6 & 1.00 \\
\hline \multirow[t]{5}{*}{$\mathrm{C} 8$} & 118 & 0.7 & 14.9 & 0.93 \\
\hline & 120 & 1.0 & 22.2 & 0.94 \\
\hline & 122 & 1.7 & 60.3 & 0.96 \\
\hline & 124 & 2.4 & 134.3 & 0.99 \\
\hline & 126 & 2.9 & 109.9 & 1.00 \\
\hline
\end{tabular}

PP: polypropylene; $\mathrm{C} 1$ to $\mathrm{C} 8$ : composites; $\mathrm{m}$ and $\mathrm{x}$ : Ozawa constants, and $\mathrm{R}^{2}$ : coefficient of determination.

Table 5. Kinetic parameters obtained for PP and the composites, T: temperature; using the Ozawa model. 


\begin{tabular}{|c|c|c|c|c|}
\hline Material & $x_{t}(\%)$ & $\mathrm{F}(\mathrm{T})$ & B & $\mathrm{R}^{2}$ \\
\hline \multirow[t]{4}{*}{ PP } & 20 & 6.7 & 1.0 & 0.99 \\
\hline & 40 & 7.4 & 1.0 & 0.99 \\
\hline & 60 & 8.2 & 1.0 & 0.99 \\
\hline & 80 & 9.0 & 1.1 & 0.99 \\
\hline \multirow[t]{4}{*}{$\mathrm{C} 1$} & 20 & 7.4 & 1.2 & 1.00 \\
\hline & 40 & 10.0 & 1.2 & 1.00 \\
\hline & 60 & 11.0 & 1.2 & 1.00 \\
\hline & 80 & 13.5 & 1.2 & 1.00 \\
\hline \multirow[t]{4}{*}{$\mathrm{C} 2$} & 20 & 6.7 & 1.2 & 1.00 \\
\hline & 40 & 9.0 & 1.2 & 1.00 \\
\hline & 60 & 10.0 & 1.2 & 1.00 \\
\hline & 80 & 11.0 & 1.1 & 1.00 \\
\hline \multirow[t]{4}{*}{$\mathrm{C} 3$} & 20 & 6.1 & 1.3 & 0.99 \\
\hline & 40 & 8.2 & 1.3 & 0.99 \\
\hline & 60 & 9.0 & 1.3 & 1.00 \\
\hline & 80 & 11.0 & 1.3 & 1.00 \\
\hline \multirow[t]{4}{*}{$\mathrm{C} 4$} & 20 & 6.7 & 1.1 & 0.99 \\
\hline & 40 & 9.0 & 1.1 & 1.00 \\
\hline & 60 & 10.0 & 1.1 & 1.00 \\
\hline & 80 & 11.0 & 1.1 & 1.00 \\
\hline \multirow[t]{4}{*}{ C5 } & 20 & 8.2 & 1.1 & 0.95 \\
\hline & 40 & 10.0 & 1.2 & 0.97 \\
\hline & 60 & 11.0 & 1.2 & 0.97 \\
\hline & 80 & 13.5 & 1.2 & 0.98 \\
\hline \multirow[t]{4}{*}{$\mathrm{C} 6$} & 20 & 8.2 & 1.1 & 1.00 \\
\hline & 40 & 10.0 & 1.1 & 1.00 \\
\hline & 60 & 11.0 & 1.1 & 1.00 \\
\hline & 80 & 12.2 & 1.1 & 1.00 \\
\hline \multirow[t]{4}{*}{ C7 } & 20 & 7.4 & 1.3 & 1.00 \\
\hline & 40 & 10.0 & 1.3 & 1.00 \\
\hline & 60 & 11.0 & 1.3 & 1.00 \\
\hline & 80 & 13.5 & 1.3 & 1.00 \\
\hline \multirow[t]{4}{*}{$\mathrm{C} 8$} & 20 & 6.7 & 1.3 & 0.99 \\
\hline & 40 & 8.2 & 1.3 & 1.00 \\
\hline & 60 & 10.0 & 1.3 & 1.00 \\
\hline & 80 & 12.2 & 1.3 & 1.00 \\
\hline
\end{tabular}

Table 6. Kinetic parameters obtained for PP (polypropylene) and its composites (C1 to C8) using the model of Liu et al. (1997). 

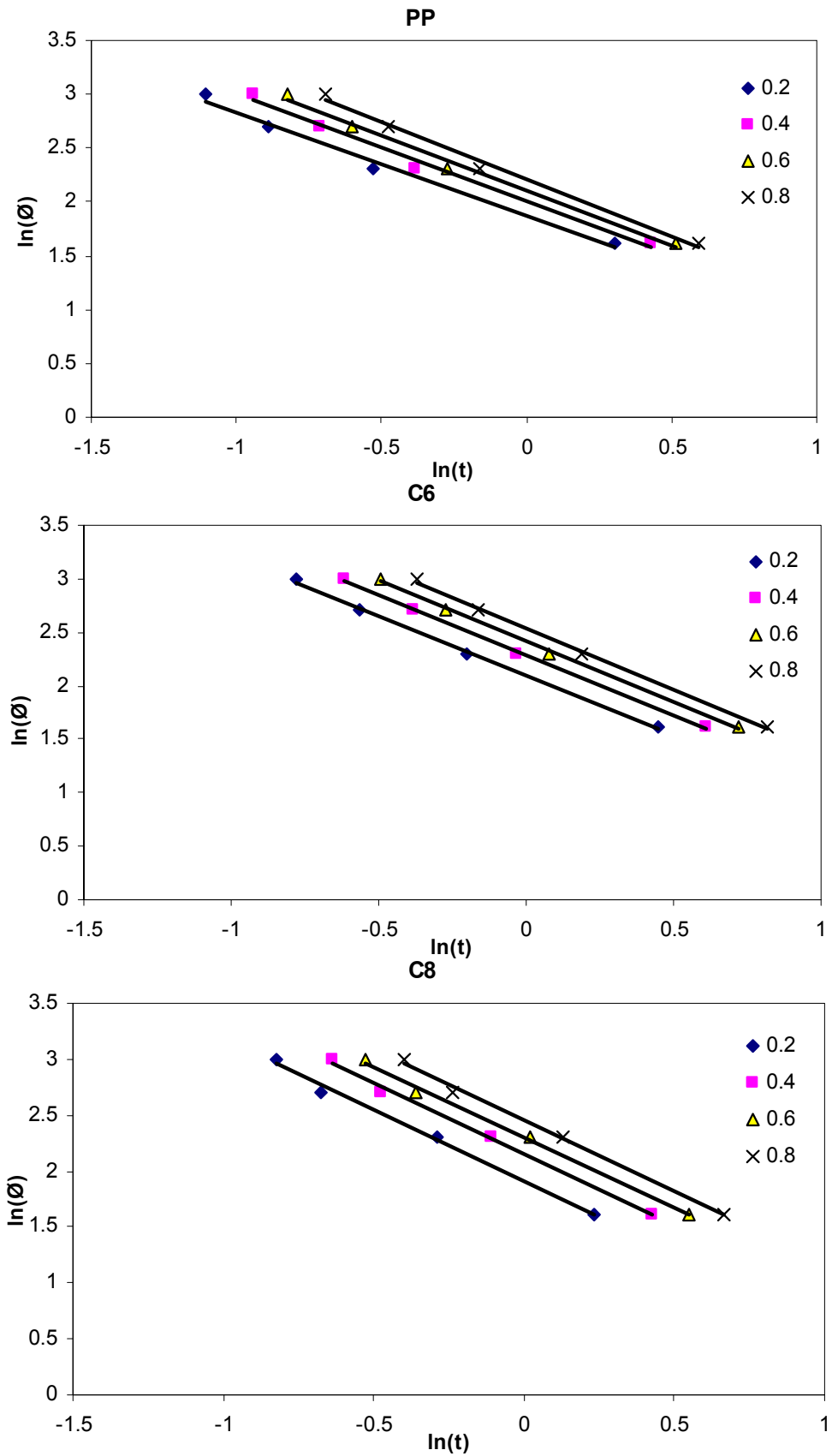

Fig. 6. Non-isothermal crystallization plots based on Liu et al. (1997) model. PP: polypropylene; C6 (PP/MAPP/Fiber: 80/5/15) and C8: (PP/MAPP/Fiber: 65/5/30). composites. 


\section{Conclusions}

From the experimental results, the following conclusions can be drawn:

1. The thermal conductivity and non-isothermal crystallization kinetics of biofiberreinforced PP composites were influenced by fiber content and chemical modifications of the biofiber.

2. The addition of fiber reduced the thermal conductivity of pure PP.

3. The biocomposites exhibited higher crystallinity, crystallization temperature, half-time but lower crystallization rate than pure PP,.

4. Composites fabricated with chemically-modified fibers exhibited lower degree of crystallinity than those reinforced with untreated fibers.

5. The addition of MAPP into the composites accelerated the crystallization process but had a negative impact on the degree of crystallinity.

6. The important process parameter of cooling rate also was strongly effective on the behaviour of crystallization in that involving higher cooling rate resulted to lower degree of crystallinity and lower crystallization temperature, but accelerated crystallization process. Activation energy of crystallization determined using Kissinger model for composites (around $300 \mathrm{~kJ} / \mathrm{mol}$ ) was much lower than that of PP (419 $\mathrm{kJ} / \mathrm{mol}$ ) in this study which is consistent with the degrees of crystallinity.

7. Analyzing the data using Ozawa and Liu et al. models resulted to a good linearity and conclusion.

\section{References}

ASTM C518. 2002. Standard Test Method for Steady-State Heat Flux Measurements and Thermal Transmission Properties by Means of the Heat Flow Meter Apparatus, Philadelphia, PA.

ANKOM Technology (2005) ANKOM Technology Method. http://www.ankom.com/09_procedures/ procedures.shtml .

Garbarczyk, J. \& Borysiak, S. (2000). Crystallization of isotactic polypropylene at surfaces of cellulose natural fibers. 3rd International Wood and Natural Fibre Composites Symposium Kassel, Germany.

Kim, S.W.; Lee, S.H.; Kang, J.S. \& Kang, K.H. (2006). Thermal conductivity of thermoplastics reinforced with natural fibers. International Journal of Thermophysics vol.27, No.6, pp. 1873-1881, ISSN 1572-9567.

Kissinger, H.T. (1957). Reaction Kinetics in Differential Thermal Analysis. Analytical Chemistry Vol.29, No.11, pp. 1702-1706, ISSN 0003-2700.

Liu, T.; Mo, Z.; Wang, S. \& Zhang, H. (1997). Nonisothermal melt and cold crystallization kinetics of poly(aryl ether ether ketone ketone). Polymer Engineering \& Science Vo.37, No.3, pp. 568-575, ISSN 1548-2634.

Lonkar, S.P.; Morlat-Therias, S.; Caperaa, N.; Leroux, F,; Gardette, J.L. \& Singh, R.P. (2009). Preparation and nonisothermal crystallization behavior of polypropylene/layered double hydroxide nanocomposites. Polymer Vol.50, No.6, pp. 1505-1515, ISSN 0032-3861. 
Mucha, M. \& Krolikowski. (2003). Application of DSC to study crystallization kinetics of polypropylene containing fillers. Journal of Thermal Analysis and Calorimetry Vol.74, pp. 549-557, ISSN 1572-8943.

Ozawa, T. (1971). Kinetics of non-isothermal crystallization, Polymer 12(3): 150-158.

Page, D.J.Y.S. \& T.G. Gopakumar. (2006). Properties and crystallization of maleated polypropylene/graphite flake nanocomposites. Polymer Journal Vol.38, No.9, pp. 920-929, ISSN 0032-3896.

Reiter, G. \& Strobl, G.R. (2007). Progress in understanding of polymer crystallization. SpringerVerlag Berlin Heidelberg. NY, USA.

Seo, Y.; Kim, J.; Kim, K.U. \& Kim, Y.C. (2000). Study of the crystallization behaviors of polypropylene and maleic anhydride grafted polypropylene. Polymer Vol.41, pp. 2639-2646, ISSN 0032-3861.

Somnuk, U.; Eder, G.; Phinyocheep, P.; Suppakarn, N.; Sutapun, W. \& Ruksakulpiwat, Y. (2007). Quiescent crystallization of natural fibers-polypropylene composites. Journal of Applied Polymer Science Vol.106, pp. 2997-3006, ISSN 1097-4628.

Zhang, X.; Xie, F.; Pen, Z. \& Zhang, Y. \& Zhou W. (2002). Effect of nucleating agent on the structure and properties of polypropylene/poly (ethylene-octene) blends. European Polymer Journal Vol.38, No.1, pp. 1-6, ISSN 0014-3057. 


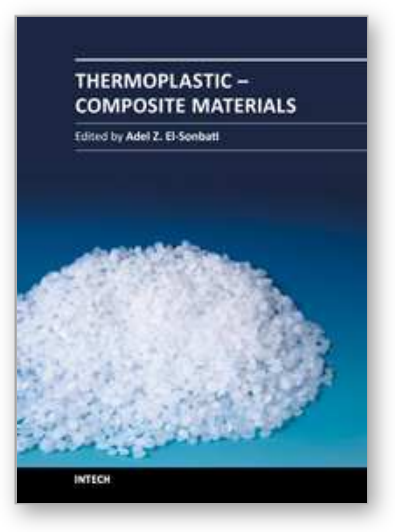

\author{
Thermoplastic - Composite Materials \\ Edited by Prof. Adel El-Sonbati
}

ISBN 978-953-51-0310-3

Hard cover, 146 pages

Publisher InTech

Published online 16, March, 2012

Published in print edition March, 2012

Composite materials often demand a unique combination of properties, including high thermal and oxidative stability, toughness, solvent resistance and low dielectric constant. This book, "Thermoplastic - Composite Materials", is comprised of seven excellent chapters, written for all specialized scientists and engineers dealing with characterization, thermal, mechanical and technical properties, rheological, morphological and microstructure properties and processing design of composite materials.

\title{
How to reference
}

In order to correctly reference this scholarly work, feel free to copy and paste the following:

M. Soleimani, L. Tabil, S. Panigrahi and I. Oguocha (2012). Crystallization and Thermal Properties of BiofiberPolypropylene Composites, Thermoplastic - Composite Materials, Prof. Adel El-Sonbati (Ed.), ISBN: 978-95351-0310-3, InTech, Available from: http://www.intechopen.com/books/thermoplastic-compositematerials/crystallization-and-thermal-properties-of-biofiber-polypropylene-composites

\section{INTECH}

open science | open minds

\author{
InTech Europe \\ University Campus STeP Ri \\ Slavka Krautzeka 83/A \\ 51000 Rijeka, Croatia \\ Phone: +385 (51) 770447 \\ Fax: +385 (51) 686166 \\ www.intechopen.com
}

\author{
InTech China \\ Unit 405, Office Block, Hotel Equatorial Shanghai \\ No.65, Yan An Road (West), Shanghai, 200040, China \\ 中国上海市延安西路65号上海国际贵都大饭店办公楼 405 单元 \\ Phone: +86-21-62489820 \\ Fax: $+86-21-62489821$
}


(C) 2012 The Author(s). Licensee IntechOpen. This is an open access article distributed under the terms of the Creative Commons Attribution 3.0 License, which permits unrestricted use, distribution, and reproduction in any medium, provided the original work is properly cited. 